Revista Iberoamericana. Vol. LXVII, Núms. 194-195, Enero-Junio 2001, 55-68

\title{
“LAS MUJERES SON LAS QUE COMÚNMENTE MANDAN EL MUNDO”: LA FEMINIZACIÓN DE LO POLÍTICO EN EL CARNERO
}

\author{
POR \\ Denise Galarza Sepúlveda \\ Emory University
}

A lo largo de su texto, Conquista y descubrimiento del Nuevo Reino de Granada, conocido popularmente como El carnero, Juan Rodríguez Freyle describe y critica los problemas del “mando” o gobierno del Nuevo Reino de Granada. Tal “mando” le pertenecía a la Real Audiencia de Santa Fe de Bogotá, institución que es el escenario central de la obra. ${ }^{1}$ En las Indias, contrario a lo establecido en España, las Audiencias Reales asumieron el papel de órganos administrativos y legislativos además de ser tribunales de justicia. ${ }^{2}$ Por eso el autor no distingue entre lo administrativo y lo jurídico, indistintamente refiriéndose a ambos con el término "mandar" cuando discute el orden político fundado por la Audiencia de Bogotá. El caótico proceder de esta institución, al igual que el de muchas Audiencias americanas, se debió tanto a los problemas inherentes en la estructura misma como a las luchas de poder entre sus integrantes. ${ }^{3}$ La pésima comunicación entre el gobernador militar de Santa Fe, los oidores locales, el conjunto de audiencias americanas y el Consejo de Indias afectaron seriamente la eficacia de la maquinaria jurídico-administrativa, y la coexistencia de múltiples focos de poder local se prestó a la corrupción y al desorden.

Sin embargo, pese a la evidente complejidad burocrática de la situación novogranadina, en su obra Rodríguez Freyle hace recaer la responsabilidad del caos de la Audiencia de

\footnotetext{
${ }^{1}$ Aunque Rodríguez Freyle hace breve mención de la época en que la ciudad de Santa Fe de Bogotá estaba bajo el cargo de la Audiencia de Santo Domingo — desde poco después de su fundación en 1538 hasta 1550 — se centra en lo ocurrido en el Reino bajo la Audiencia de Bogotá desde su fundación en 1550. Los representantes de ésta última son el blanco de su crítica.

${ }^{2}$ Para un estudio sobre el papel de las Reales Audiencias en el Nuevo Mundo, véase Rafael Gómez Hoyos, Las Leyes de Indias y el derecho eclesiástico en la América Española y las Filipinas.

${ }^{3}$ Después de llevar a cabo un estudio detallado sobre la Audiencia de Manila, Charles Henry Cunningham ofrece varias razones para el fracaso de las Audiencias americanas en general. Según elabora en su texto, The Audiencias in the Spanish Colonies As Illustrated by the Audiencia of Manilla, el fracaso jurídico-administrativo de la Audiencia no se debió únicamente a la avaricia de sus representantes, sino la estructura del sistema mismo. Por ejemplo, la posibilidad de apelar cualquier decisión al Consejo de Indias-parte integral de dicho sistema—estorbó gravemente la ejecución inmediata de decisiones legales. Además, existían luchas de poder entre el gobernador y los oidores de la Audiencia como resultado de la falta de preparación jurídica de aquél, su consecuente dependencia de los oidores y las luchas de poder entre éstos. Todo esto contribuyó al caos que caracterizó a la Audiencia de Bogotá.
} 
Bogotá - y por extensión del Nuevo Reino — sobre la figura de la mujer. Cuando ha sido estudiada, la condena de la mujer por el autor se ha considerado el simple reflejo de una actitud misógina propia de su momento histórico y de su formación intelectual. ${ }^{4}$ Una excepción notable es el estudio reciente de Ivette Hernández-Torres en el que se analiza el discurso misógino como parte integral de la obra y se sostiene que tal discurso permite la contaminación mutua del espacio público y el privado. A pesar de que Hernández-Torres señala la utilidad narrativa de la misoginia en la obra, ella concluye que ese discurso "posibilita el impugnar ambas esferas, tanto la privada como la pública, porque en ambas mandan las mujeres” (Hernández-Torres 168, el subrayado es mío). Es precisamente esta fácil aseveración sobre el mando de la mujer la que se cuestiona en el presente ensayo. Un análisis detallado del papel que el autor le otorga a la mujer en diferentes situaciones jurídico-administrativas y de los momentos narrativos en que éste recurre a la misoginia demostrará que los ataques a la mujer se utilizan para efectuar una crítica radical del mundo político novogranadino.

La figura femenina aparece por primera vez cuando Rodríguez Freyle describe la estructura política de los indígenas, o sea "el orden y estilo que tenían” (64). Se trata, según el autor, de un antiguo sistema jurídico-administrativo equiparable al español en que la monarquía indígena era compartida: “Guatavita en la jurisdicción de Santa Fe, y Ramiriquí en la jurisdicción de Tunja” (65). Según se narra, bajo esos “príncipes” existía un sistema jerárquico compuesto por otros caciques:

Unos con sobrenombres de ubzaques, a quien pertenece el nombre de duques; otros se llamaban guayques, que es lo propio que decimos condes o marqueses; y los unos y los otros muy respetados de sus vasallos, y con igual jurisdicción en administrar justicia, en cuanto con su entendimiento la alcanzaban. (65, el subrayado es mío)

El autor equipara el gobierno indígena con el español no sólo mediante el uso de términos propios a la corte española (duques y marqueses), sino resaltando a la vez una característica particular de la burocracia colonial española: el reino de Guatavita se presenta como regido por un sistema jurídico primitivo que tiene simultáneamente una dimensión administrativa.

Es de notar que en este contexto político intrínsecamente paralelo al español, la mujer indígena ya aparece representada como un peligro y amenaza al orden social:

Guatavita [...] no tenía más que una ley de justicia, y ésta escrita con sangre [...] si dentro de su palacio o cercado algún indio ponía los ojos con afición a alguna de sus mujeres, que tenía muchas, al punto y sin más información, el indio y la india morían por ello. (65)

Desde el primer momento en que aparece en la historia, la mujer indígena se relaciona con la prohibición que emanaba de la que, según Rodríguez Freyle, era la única ley escrita

\footnotetext{
${ }^{4}$ Jaime Delgado concluye que la postura antifemenina del autor no es más que un síntoma histórico, mientras que Gloria M. Ortiz es un tanto más crítica y sostiene que la actitud del autor hacia la mujer es ambivalente. Para un discusión extensa de los estudios sobre el trato de la mujer en El carnero, véase la tesis doctoral de Ivette Hernández-Torres, El contrabando de lo secreto: la escritura de la historia en El carnero de Juan Rodríguez Freile; en particular las páginas 137-40.
} 
que existía en el reino del cacique Guatavita. El espacio físico del cercado real no logra suprimir la "afición” de los indios por las mujeres ni tampoco ordenar los impulsos del propio cacique. El autor explica el derrocamiento de Guatavita por su teniente de guerra Bogotá alegando que los subordinados de Bogotá se rebelan cuando entienden que, distraído por sus mujeres, Guatavita ha desatendido su reino y sus responsabilidades. Los capitanes y soldados de Bogotá

hicieron una muy célebre [fiesta] en el cercado del teniente Bogotá [...] diciéndole que él [Bogotá] sólo había de ser el señor de todo y a quien obedeciesen todos, porque Guatavita sólo servía de estarse en su cercado con sus teguyes, que es lo propio de mancebas, en sus contentos sin ocuparse de la guerra. (69, subrayado original)

Aun en su pasividad, la mujer indígena representa un peligro para el reino de Guatavita porque al entregarse el cacique a los “contentos” de las mancebas éste pierde la capacidad de cumplir con sus responsabilidades políticas. Guatavita descuida su mando y Bogotá, que en principio estaba sujeto al cacique, usurpa su poder.

Rodríguez Freyle prosigue su crítica del desorden que causa la mujer con una censura cada vez más explícita. Interrumpe su descripción del mundo indígena para apelar a la transgresión femenina por excelencia: la tentación de Adán: ${ }^{5}$

Puso Eva los ojos en aquel árbol de la ciencia del bien y del mal y enderezó a él; el demonio, que le conoció el intento, ganóle la delantera y esperóla en el puesto donde, en allegando Eva, tuvieron conversación, y entre los dos departieron las dos primeras mentiras del mundo. (79)

Rodríguez Freyle inculpa a Eva cuando explica que ésta deseaba comer del árbol vedado sin que el diablo tuviese que engañarla, ya que él "le conoció el intento" antes de hablarle (79). Adán, que no figura en este intercambio nefasto, aquí queda absuelto de toda culpabilidad:

Acometido Adán por la parte más flaca, quiero decir, rogado e importunado de una mujer hermosa, y si acaso añadió algunas lágrimas a la hermosura, ¿qué tal lo pondría? Al fin, él quedó vencido y fuera de la amistad de Dios, y Lucifer gozoso y contento. (80, el subrayado es mío)

\footnotetext{
${ }^{5}$ Después de describir la caída del hombre, Rodríguez Freyle menciona el dominio del diablo sobre los indígenas y las tierras americanas. Parecería que el autor intenta establecer una causalidad entre la caída del hombre y las prácticas paganas de los indígenas. Tal es la interpretación de estudiosos como Charles Bruno y Chang-Rodríguez. Sin embargo, en su análisis de la metáfora de la "doncella huérfana”, Susan Herman rechaza la idea de que las alusiones bíblicas—representadas por la metáfora de "ropas y joyas prestadas"—sirva únicamente a un fin moralizante: "En breve, son falsas: son adornos puestos en el texto para engañar. Las moralejas cristianas son trampas que desvían al lector no curioso" (Herman 84). Yo añadiría que este cuento bíblico tiene una función pragmática, pues está compuesto de un vocabulario jurídico-administrativo que cobra significado a la luz de la segunda parte de El carnero.
} 
Según esta interpretación, la hermosura de Eva es responsable de la primera violación de la jerarquía primordial. Gracias a ella, el hombre queda vencido y la obediencia que le debía a Dios es usurpada por el Diablo. Como el ejemplo indígena, el “caso” bíblico de la caída ilustra la capacidad femenina de alterar el orden jerárquico vigente, y en ambos, dicho poder se funda en dos excesos femeninos: "sus contentos" y "la hermosura". Juntos, estos primeros relatos establecen unas historias originarias que le servirán a Rodríguez Freyle de fundamento para sus subsiguientes y múltiples comentarios sobre la manera en que la mujer - por su naturaleza excesiva- obstaculiza e interrumpe la armonía social en el Nuevo Reino de Granada.

Cuando en El carnero Rodríguez Freyle pasa a narrar los acontecimientos en el contexto novogranadino, él interrumpe esa narración repetidas veces para insertar múltiples digresiones sobre la naturaleza incitadora e instigadora de la mujer hermosa:

¡Oh hermosura desdichada, mal empleada, pues tantos daños causaste por no corregirte con la razón! (144)

$\mathrm{Y}:$

Quien comúnmente manda el mundo son mujeres [...] ¿Cómo se le puede quitar a la mujer que no mande, siendo suya la jurisdicción, porque es primera en tiempo, por la cual razón es mejor en derecho? Demás que le viene de herencia; pruébolo: Mándale Dios a Adán: “No comas del árbol que está en el medio del paraíso [...]” Pues Eva, su mujer, va y tráele la fruta, y mándale que coma de ella, y obedece Adán a su mujer. (244, los subrayados son míos)

Varios estudios sobre El carnero han señalado superficialmente las digresiones de Rodríguez Freyle sobre el mando de la mujer y el caos que causa en el mundo como simple misoginia. Quisiera proponer aquí que estos comentarios tienen un carácter subversivo que se desprende del contexto político-administrativo en que se sitúa a la mujer. El uso de las palabras “manda”, “jurisdicción” y “derecho” en la cita anterior hace resaltar la alusión al sistema administrativo de la Audiencia. Es en este ámbito donde Rodríguez Freyle coloca a la mujer hermosa para luego atribuirle el aluvión de problemas políticos locales que se describirán en la segunda parte de la obra.

La segunda sección comienza con el conocido caso de la negra bruja llamada Juana García, narración que resulta paradigmática en su articulación del peligro que representa la naturaleza excesiva de una mujer hermosa. Rodríguez Freyle dice haber incluido el caso para explicar un anuncio misterioso: un papel puesto en las paredes del Cabildo que proclamaba la muerte por ahogo de unos oidores que viajaban a España, antes de que se supiese que se había hundido el navío que los transportaba. Aunque la autora del papel fue la bruja, el proceso inquisitorial en su contra se lleva a cabo no por esta acción, sino porque Juana había empleado su brujería a petición de una hermosa adúltera que quería saber cuándo su marido regresaría de viaje para así decidir si tendría que abortar su bebé bastardo. Cuando el marido de "la hermosura" descubre este acto de brujería el inquisidor investiga, obliga a deponer a "otras muchas mujeres” además de Juana y sus hijas, y pronuncia sentencia contra todos los culpados: 
Corrió la voz de que eran muchos los que habían caído en la red, y tocaba en personas principales. En fin, el Adelantado don Gonzalo Jiménez de Quesada, el capitán Zorro, el capitán Céspedes, Juan Tafur, Juan Ruiz de Orejuela y otras personas principales acudieron al señor obispo, suplicándole no se pusiese en ejecución la sentencia. (129)

El caso de Juana García — típicamente estudiado por separado como relato mágicose analiza aquí en conjunto con los demás expedientes y relacionado con la condena que se hace de la mujer a lo largo de la obra. ${ }^{6}$ Las protagonistas principales de este primer caso son mujeres dadas a distintos excesos ${ }^{7}$ (la adúltera hermosa, Juana García, sus hijas y las otras), y se explica que ellas tejen una red para atrapar a "personas principales”, o sea, los hombres de las más altas esferas.

Rodríguez Freyle comienza el próximo caso con otra denuncia de la hermosura femenina como instigadora de desgracias y delitos. Se trata esta vez de una criolla rica, doña Inés de Hinojosa, una "mujer hermosa por extremo" que vivía descontenta con su marido mujeriego y jugador (136). Ella se enreda en "amores torpes" con Jorge Voto, maestro de danza, con el resultado de que el maestro mata al marido y doña Inés se va a vivir con él a otro pueblo. Allí, doña Inés tiene amores con un segundo hombre, Pedro Bravo de Rivera quien a su vez mata a Jorge Voto. En la siguiente oración, el autor presenta a la hermosura como agente de desgracias:

[...] la hermosura de doña Inés llamó a sí a don Pedro Bravo de Rivera (con razón llamaron a la hermosura "callado engaño", porque muchos hablando engañan, y ella, aunque calle, ciega, ceba y engaña). (137)

A pesar de que son los hombres los que cometen los homicidios, éstos son instigados, según el narrador, por la "hermosura de doña Inés".

La mayoría de los casos que siguen involucran a representantes jurídicos de todos los niveles. En ellos se repite un paradigma según el cual Rodríguez Freyle atribuye el desorden o escándalo retratado a la naturaleza incitadora de la mujer hermosa, criatura destinada a alterar todo orden a causa de su herencia genesíaca. ${ }^{8}$ El conjunto de las primeras viñetas

\footnotetext{
${ }^{6}$ Para algunos estudios sobre los elementos fantásticos de este relato véanse Raquel ChangRodríguez, "Realidad y fantasía en El carnero"; y James J. Alstrum, "The Real and the Marvelous in a Tale from El carnero".

${ }^{7}$ Según los estudiosos de la época, la mujer era más susceptible a practicar brujería por un aspecto particular de su naturaleza defectuosa: sus pasiones descontroladas y excesivas. Citando el Malleus Maleficarium - documento sobre la brujería que se adoptó como texto autorizado por la Iglesia Católica a finales del siglo XV - Nancy Tuana explica las nociones de la época sobre la causa subyacente de la brujería: "Just as through the first defect in their intelligence they are more prone to abjure the faith; so through their second defect of inordinate affections and passions they search for, brood over, and inflict various vengeances, either by witchcraft or by some other means” (Tuana 59, el subrayado es mío). Es decir, su excesiva sexualidad inclinaba a la mujer hacia la brujería.

${ }^{8}$ El tercer caso trata de la deshonra del oidor Andrés Cortés de Mesa; el cuarto de las travesuras del alguacil Juan Roldán; el quinto de los amores ilícitos del fiscal Orozco; el sexto de los de la esposa del fiscal Gaspar de Peralta; el séptimo trata las infidelidades de Luisa Tafur; el octavo los amores del corregidor Antonio de Quiñones; y el noveno es sobre el fratricidio que comete Juan de Mayorga,
} 
establecerá un esquema retórico que alcanzará su mayor expresión en el núcleo narrativo de la obra, el quinto caso. ${ }^{9}$

Justo antes de presentar los detalles del quinto expediente, el autor culpa directamente a la mujer hermosa por los “males”, es decir el caos, que prevaleció en la Real Audiencia.

Siempre me topo con una mujer hermosa que me dé en qué entender. Grandes males han causado en el mundo mujeres hermosas. Y sin ir más lejos, mirando la primera, que sin duda fue la más linda, como amasada de la mano de Dios, ¿qué tal quedó el mundo por ella? (177)

Pero la amenaza de Eva, y por extensión la de toda mujer, no se fundamenta únicamente en su hermosura sino también en la amenaza representada por su desplazamiento físico. Recordemos que cuando explica el papel que desempeñó la hermosura en la pérdida del paraíso, Rodríguez Freyle exclama: "Qué caro le costó a Adán la mujer, por haberle concedido que se fuese a pasear” (80). Luego, retomando este mismo “caso” el autor recurre a un refrán popular para pronunciar su sentencia: "No la dejárades vos irse a pasear, que aquí estuvo todo el daño. La mujer y la hija, la pierna quebrada y en casa” (244). Rodríguez Freyle se refiere directamente al poder que tiene sobre el hombre la hermosura, el cual se agudiza cuando se une a otro exceso femenino, el movimiento. Aunque no utiliza las palabras "doméstico" y "político" para referirse a los espacios femenino y masculino respectivamente, sus vituperaciones contra la hermosura reflejan el peligro que representa el movimiento de la mujer en el espacio público. La mujer es un agente perjudicial al sistema político pues induce a que se franquee la línea divisoria entre lo doméstico y lo político. El autor comienza el quinto caso señalando precisamente cómo los "paseos" de una mujer hermosa revuelven el orden jurídico-administrativo de la colonia.

Se cuenta que el fiscal Orozco mantenía relaciones ilícitas con una dama hermosa, rica y casada. Los celos de su esposa, la "señora fiscala”, la llevan a darle quejas al visitador Monzón sobre el comportamiento adúltero de su marido. La "fiscala" sale de la esfera doméstica a la pública con el fin de pedir ayuda oficial para restablecer la armonía de su hogar, que ha sido violentada por una mujer hermosa. La entrada de la esposa del fiscal en el espacio político provoca que el visitador Monzón se adentre en el doméstico y hable con la amante del fiscal Orozco. El visitador intenta convencer a la amante de que abandone sus amores, obteniendo el siguiente resultado:

de los toques y respuestas salió el visitador [Monzón] muy enfadado, y ella [la amante] se convirtió en un áspid ponzoñoso; de tal manera, que visitándola el fiscal [Orozco], le dijo que le había de dar la cabeza de Monzón, o que no le había de atravesar los umbrales de

alcalde ordinario. Esta lista incluye los casos más extensos, o los que le sirven al autor para elaborar sus comentarios y juicios.

${ }^{9}$ El quinto caso ocupa un lugar central en la obra tanto por su posición en el texto como por ser el caso más extenso. En éste, Rodríguez Freyle elabora detalladamente el papel de cada uno de los personajes — por ejemplo el del visitador Monzón, del alguacil Juan Roldán y del alcalde Sepúlveda— aun cuando eso complica su relato. En conjunto, estos hilos narrativos representan un desarrollo del que carecen los demás casos. 
su casa; con lo cual le pareció al Orozco que ya quedaba privado de sus gustos. Este fue el principio y origen [...] de los muchos alborotos que tuvo esta ciudad. (178, el subrayado es mío)

El autor emprende la narración de este caso (como en las historias originarias — la indígena y la bíblica - descritas al comienzo de este ensayo) inculpando a la mujer. El "principio y origen" de los alborotos se le atribuyen al "áspid ponzoñoso", ya que ésta coacciona al fiscal Orozco para que mate al visitador. El caos jurídico-administrativo que se desata en el resto del caso revuelve la jerarquía de la Audiencia pues Monzón —cuya visita tenía el fin expreso de enjuiciar a sus oficiales — es él mismo perseguido y encarcelado por algunos de ellos.

Rodríguez Freyle denuncia así a las mujeres en general como origen y causa del desorden político de la colonia. Sin embargo, hay una paradoja fundamental en su representación de la mujer. Desde las teguyes del cacique Guatavita, pasando por Eva y hasta doña Inés, se hará patente una misma vacilación en la presentación de la subjetividad femenina. ${ }^{10}$ Por ejemplo, a pesar de la capacidad amenazadora que el autor le había atribuido a la mujer indígena al comienzo de la obra, la agencia de esta última se reduce finalmente a su corporalidad, a sus “contentos”. Además, según la única ley escrita del reino de Guatavita, la mujer queda implicada como instigadora, haya ésta correspondido o no al indio que la ha mirado. Ella es castigada por ese delito—-lo cual sugiere su responsabilidad—pero en realidad es un objeto deseado que provoca la mirada de los indios que la rodean. El único otro delito que Rodríguez Freyle menciona en esta narración es “el hurto [que] fue siempre castigado por ellos” (65), lo cual subraya que en el sistema jurídico indígena la mujer ocupa el lugar de una cosa hurtada. El decreto primordial del cacique y la correspondiente sentencia proponen a la mujer como un objeto al que, paradójicamente, se le atribuye subjetividad y responsabilidad legal. Dicho de otro modo, la responsabilidad que se le atribuye a la mujer indígena depende de su condición de objeto en un sistema legal que se fundamenta en la agencia del hombre. Cercada por el rey, la mujer indígena es deseada por otros indios y sujeta a un mandato que la cosifica a la vez que le imputa responsabilidad legal. Las mujeres de Guatavita representan por un lado el poder y el rango del cacique, pero a la vez el autor les atribuye la capacidad de desestabilizar ese poder. En este esquema la agencia femenina es paradójica como tal porque depende de su misma pasividad y subraya la agencia masculina subyacente. Aunque la agencia masculina —específicamente el comportamiento del cacique y la reacción de los soldados y de Bogotá— es responsable por la revolución contra Guatavita, se sugiere que los contentos de las mancebas lo incitan a abandonar sus responsabilidades políticas.

De igual modo, al principio de la obra el autor le asigna responsabilidad absoluta a Eva por el engaño primigenio, pues el demonio “le conoció el intento” (79). La agencia asignada

\footnotetext{
${ }^{10}$ A pesar de la agencia maligna que el autor les había atribuido a las mujeres, aun los casos como el de Juana García llegan a implicar a personas de las más altas esferas sociales y aun a ciertos representantes de la Corona. Este primer expediente deja al descubierto cómo los capitanes manipulan el sistema jurídico para tergiversar la “justicia”, convenciendo al inquisidor de que sólo se castigue a Juana para exonerarse ellos, y logrando cambiar la sentencia para proteger a una red de "personas principales”.
} 
a Eva podría ser un simple lugar común de la época ya que sirve únicamente para exponer cómo la primera mujer provocó la pérdida de la armonía paradisíaca. Sin embargo, el lenguaje que Rodríguez Freyle emplea para atribuirle agencia a Eva revela otra vez una tensión paradójica. El autor comienza explicando las consecuencias del diálogo entre Eva y el diablo, achacándole intencionalidad a aquélla: “el diablo, que le conoció el intento, ganóle la delantera” (80). Poco después anuncia el resultado: "Eva salió vencida y engañada, y ella engañó a su marido” (80). Tanto el contraste entre estas dos citas como la rápida transición del participio al verbo activo en la segunda cita ilustran cómo Eva es transformada de agente a víctima, y de víctima a instrumento diabólico. Este vaivén —que refleja la tensión paradójica del poder femenino - se repite en otros momentos. Por ejemplo, Rodríguez Freyle insiste en que Eva tomó parte activa en pronunciar una de las primeras mentiras del mundo - equiparando su poder al del diablo- pero inmediatamente después la reduce a la condición de objeto: “y si acaso añadió algunas lágrimas a la hermosura, ¿qué tal lo pondría?” (80). ${ }^{11}$ Al relegar a Eva a la simple condición de cuerpo, la voluntad de la primera mujer es reducida a una sinécdoque, es decir, a una abstracción representada por "la hermosura".

Igualmente, al narrar el quinto caso, Rodríguez Freyle insiste en culpar a la mujer por los delitos que se cometieron en el Nuevo Reino; pero el poder que se le concede a doña Inés está fundamentado en su cuerpo, al igual que en los ejemplos indígena y bíblico. Aquí, la mujer priva al fiscal de sus gustos hasta que éste le lleve la cabeza del visitador Monzón: "Demanda rigurosa fue la de esta mujer y dama, que, siendo hermosa, da en cruel, eslo de veras; y más si aspira a la venganza” (179). No obstante, esta explicación del origen del consiguiente caos político queda subvertida cuando el autor describe la complicada red de acciones ilegales de Orozco y de los otros representantes jurídicos, la cual paso a resumir.

No conforme con cumplir la petición de doña Inés, el fiscal Orozco decide matar de una vez al esposo de su amante, capitán de una escuadra de a caballo, además de a Monzón. Con este fin, Orozco hace correr el rumor de que se prepara un alzamiento en el Nuevo Reino. Cuando se magnifica el rumor hasta afirmar que un gran número de indios, mulatos, mestizos, negros e ingleses se han amotinado, el Nuevo Reino se moviliza: se crean compañías de infantes, se nombran capitanes, y se solicita la ayuda de otras ciudades cercanas para suprimir esa supuesta amenaza. Para darle credibilidad al alzamiento, Orozco falsifica una correspondencia entre Monzón y su amigo, el poderoso cacique don Diego de Torres, y hace circular las cartas apócrifas públicamente. Una vez que arrastra la voluntad del oidor Zorrilla, el fiscal encarcela al cacique, a sus amigos y parientes, y a los familiares de Monzón. Luego escribe otras cartas anunciando la cercanía del levantamiento con lo cual salen huyendo "las pobres mujeres con sus criaturas por calles y campos” (181). Complicando el desorden narrativo, el autor menciona cómo el capitán (esposo del “áspid ponzoñoso”), decide salir de la ciudad aunque no tiene conocimiento de lo que ocurre.

Dado el ambiente intrigante, el capitán sigue el consejo del alcalde Nicolás de Sepúlveda, y, antes de retirarse con su mujer a su hacienda, esconde su extensa colección

\footnotetext{
${ }^{11}$ Para un análisis del intercambio entre Eva y el diablo véase el artículo "Conquest and Discovery: Subversion of the Fall in El carnero", de Susan Herman, en que este primer encuentro se interpreta como una alusión velada al acto sexual y, consecuentemente, como el primer caso de adulterio.
} 
de armas en casa de otro capitán para no ser falsamente acusado de participación. Por su parte Monzón recurre a la ayuda del picaresco alguacil Juan Roldán para sacar al cacique don Diego de Torres de la cárcel. Éste, con la ayuda de un herrero y una pastelera, le hace llegar a don Diego las herramientas necesarias para el escape. Los representantes jurídicos encarcelan a Roldán para averiguar lo que sabe de la fuga del cacique, y éste declara la verdad, "empezando por los amores del fiscal Orozco y diciendo cómo ellos eran causa del fingido alzamiento” (187). Aparte del secretario, los únicos representantes de la Audiencia que se hallan presentes para tomar la declaración son Orozco mismo y su cómplice Zorrilla. Como había de esperarse, "la Audiencia" no toma cartas en el asunto, sino que manda a encarcelar a Monzón. Cuando se averigua que la vida de Monzón corre peligro en la cárcel, un fraile y el regidor Sepúlveda intentan protegerlo, y también terminan encarcelados.

Cuando Sepúlveda consigue su libertad y la de los otros hombres injustamente encarcelados, no la recupera revelando la verdad, sino atribuyéndole falsamente el alzamiento a Orozco. Según cuenta Rodríguez Freyle, el regidor

dejó sin máscara el amancebamiento del licenciado Orozco, y que por su causa estaba revuelta la tierra [...] siendo sólo el fiscal el autor de tales movimientos y escándalos [...] y que para en prueba de lo que tenía dicho, se hallarían en casa del capitán fulano mucha cantidad de armas [...] recogidas allí por orden del dicho fiscal. (197)

Como revelación de causa, el amancebamiento del fiscal Orozco carece de verdadera importancia ya que el alguacil Roldán había dejado claro que era vox populi. Sepúlveda utiliza la información que su amigo el capitán le había confiado y distorsiona la justicia para hundir a Orozco. Es decir, este "movimiento y escándalo" de Sepúlveda acaba con el movimiento y escándalo del fiscal apasionado.

Después que expone los diferentes hilos de esta enmarañada narrativa, Rodríguez Freyle continúa describiendo la Audiencia. Delinea doce condiciones que debería tener el buen juez con el fin de que "veamos agora si topan algunas de estas doce condiciones en los jueces de este gobierno” (243). Pero, en lugar de llevar a cabo esta prueba, se aparta de su descripción del gobierno local y declara:

¿Qué diferencia hay entre mandar las mujeres la república, o mandar a los varones que mandan las repúblicas? Las mujeres comúnmente son las que mandan el mundo; las que se sientan en los tribunales y sentencian y condenan al justo y sueltan al culpado; las que ponen y quitan leyes y ejercitan con rigor las sentencias; las que reciben dones y presentes y hacen procesos falsos. (245)

Esta atribución del mando del mundo a la mujer suena hueca, especialmente cuando se considera que aparece inmediatamente después de haber concluido la descripción de la complicada red de engaños, traiciones y delitos llevados a cabo por los hombres en el quinto caso. Desde la injusta condena del cacique a manos de Zorrilla y Orozco hasta el falso proceso que se inventan tanto Orozco con sus cartas falsificadas como Sepúlveda con sus calumnias, los hombres son los verdaderos agentes de estos delitos y abusos y, por 
añadidura, del caos que resulta. ${ }^{12}$ Cada uno de los hechos atribuidos a la mujer es efectuado en realidad por un representante jurídico, por una persona principal de la colonia.

Las vueltas de este caso subrayan la extensa manipulación de la Real Audiencia mediante una complicada red de intrigas que es efectuada aquí por los hombres, y menoscaban la insistencia del autor en la amenaza al orden público representada por la mujer:

El fiscal quería que el marido de su dama muriese también, y ella quería que la mujer de su galán también muriese [...] La casa donde sola la voluntad es señora, no está segura la razón [...] Esto fue el origen y principio de los disgustos de este Reino y pérdidas de haciendas, y el venir de visitadores y jueces, polilla de esta tierra y menoscabo de ella...Callar es cordura. (179)

La frase "origen y principio" — antes empleada en orden invertido para tachar a la amante del fiscal Orozco de "principio y origen" del caos novogranadino— se emplea aquí para denunciar a los visitadores y los jueces. Al examinar el quinto caso detalladamente, se hace patente que la mujer tiene un papel mínimo en los acontecimientos novogranadinos que se narran. La autocensura del autor, “callar es cordura”, representa un doble gesto que, con pretensiones de velar la crítica, termina resaltando el hecho de que los representantes jurídicos han sido "polilla de esta tierra y menoscabo de ella”. Cada vez que Rodríguez Freyle se aparta de la exposición de los casos para criticar el sistema colonial de manera directa, se defiende apelando a la virtud de la reticencia. ${ }^{13}$

A mi ver, es precisamente de ahí que surge la conexión entre la mujer y el sistema jurídico propuesta en El carnero: el autor recurre a la mujer como vehículo de sus críticas ante el peligro que representaría el sostener una crítica directa al sistema colonial. ${ }^{14}$ Rodríguez Freyle comienza pronunciando sus juicios en contra de la mujer, pero termina dirigiendo sus reprimendas hacia "la hermosura". ${ }^{15}$ Le atribuye el poder de la mujer

${ }^{12}$ Estas denuncias (desde condenas injustas a procesos falsos) ocurren cuando ya el autor ha emprendido la descripción de la Audiencia bajo el presidente Francisco Sandi. Sin embargo, por su especificidad esta divagación recuerda y señala al quinto caso.

${ }^{13}$ Después de pronunciar un juicio o una crítica tajante, el autor emplea repetidas veces un gesto parecido al anterior: "Yo no he de juzgar si hizo mal o bien, porque no me quiero meter en la jurisdicción del agua, no me coja algún remolino y me pique” (234).

${ }^{14}$ Sólo hay que recordar el caso que el autor narra sobre el hallazgo de los libelos infamatorios contra los miembros de la Audiencia de Santa Fe que fueron escritos por un oidor de la misma Audiencia, Andrés Cortés de Mesa. Éstos causaron escándalo y resultaron en la tortura de un hombre y la muerte de dos inocentes. Quisiera sugerir que aun dada la circulación clandestina de la obra, el autor tendría que velar sus críticas porque, en el caso de ser confiscada por las autoridades, su manuscrito se podría calificar como papeles infamatorios y se le podría condenar a muerte por difamar a los miembros de la Real Audiencia de Bogotá.

${ }^{15}$ En las subsiguientes narraciones, la mujer hermosa aparece como producto novogranadino y regalo de Dios, como diablo que asume la forma de mujer hermosa, como víctima de fratricidio, y como partícipe en un triángulo amoroso. A todas las mujeres hermosas que aparecen en la obra, aun a aquélla que es asesinada por su hermano, el autor les atribuye culpabilidad: esta última aparece presentada primero como víctima, denunciando a su hermano homicida, pero después el autor entona la misma 
indígena a "sus contentos" mientras que el poder de las españolas y criollas reside en su "hermosura”, o sea, para todas recurre al lugar común sobre la sexualidad exagerada de la mujer. El atribuirle una subjetividad a la mujer que se fundamenta precisamente en su condición de objeto o abstracción vuelve problemática la agencia desordenada que el autor le achaca a la mujer. Llevada a sus últimas consecuencias, esta paradójica representación de la mujer señala al hombre como verdadero responsable del desorden social. ${ }^{16}$

La representación de la mujer como exageradamente corporal tiene su fundamento en la división platónica que le atribuye una esencia racional y templada al hombre y una naturaleza pasional y excesiva a la mujer. ${ }^{17}$ En vez de hacer resaltar el papel de la mujer, los casos en realidad ponen de relieve la manera en que el sistema jurídico es manipulado directa o indirectamente por hombres “apasionados". El caos político resulta cuando estos hombres principales, desde el cacique Guatavita hasta el licenciado Orozco, abandonan su estado "natural" - léase racional—-para regocijarse en placeres carnales. ${ }^{18}$ En este sentido, su comportamiento se asemeja al comportamiento atribuido a la mujer en lo que se podría denominar la feminización de ciertas figuras políticas. En la narración de Rodríguez Freyle, la moderación que es debida de los miembros de la Audiencia (como hombres y como representantes de la ley y del sistema administrativo español) es reemplazada por una serie de excesos que amenazan la estabilidad del mismo sistema jurídico-administrativo que los define. En pocas palabras, Rodríguez Freyle pronuncia sus juicios en contra de esta “feminización” del espacio político a manos de algunos “apasionados”.

Como ejemplo paradigmático, Adán termina recibiendo un regaño explícito de parte de Dios y del narrador por no haber controlado el "pasear” de Eva:19

letanía sobre el poder nefasto de la mujer hermosa. Este trato inconsistente también vuelve sospechosa la crítica del autor.

${ }^{16}$ En uno de sus estudios, Raquel Chang-Rodríguez ha notado que por momentos el autor es explícito en sus críticas, fenómeno que ella describe como un quitarse las "máscaras” que éste emplea a lo largo de su obra ("Las máscaras de El carnero").

${ }^{17}$ Para un análisis histórico de la naturaleza femenina según varias ramas del pensamiento occidental, véase el trabajo de Nancy Tuana, The Less Noble Sex: Scientific, Religious and Philosophical Conceptions of Woman's Nature.

${ }^{18}$ Tuana discute las ideas elaboradas por Platón en Timaeus. Es de notar que el mito originario de Platón describe un mundo habitado exclusivamente por hombres. Este predominio absoluto se perdió cuando aquéllos hombres que no controlaban sus emociones, apetitos o impulsos corporales volvieron al mundo reencarnados como mujeres. Según esta narración, "[woman] exists as a result of evil, the rule of passion” (Tuana 7). A partir de ese mito, el deber del hombre era preservar su estado racional y a la vez regular la naturaleza apasionada de la mujer ya que ella no tenía el poder de controlar los impulsos asociados con el cuerpo.

${ }^{19}$ Basándose en las referencias bíblicas, algunos críticos como Chang-Rodríguez han concluido que el autor persigue como meta la crítica de su sociedad cuando percibe que ésta se desvía del marco cristiano y católico. (Chang-Rodríguez, Las máscaras de El carnero 49). Sin embargo, el uso subversivo de la ironía por parte del autor crea un suelo movedizo que difícilmente se aviene con una condena moralizadora basada en una oposición estática entre el bien y el mal. Por otro lado, el uso estratégico de lo cristiano se hace patente en la forma en que Rodríguez Freyle reescribe los cuentos bíblicos utilizando términos jurídico-administrativos, y específicamente el caos social creado por la mujer: "Hasta este punto no hallo yo en la Escritura lugar alguno que me diga que Adán hubiese mandado cosa alguna; luego de la mujer es la jurisdicción en el mandar.” [...] (244) 
Llama Dios a Adán a juicio, y dale por disculpa, diciendo: Mulier quem dedisti mihi, ipsa me decepit. Anda, señor, que no es ésa la culpa de vuestra golosina; no la dejárades vos irse a pasear, que aquí estuvo el daño. (244, subrayado original)

De nuevo se unen los dos excesos, la hermosura y el movimiento de la mujer, pero ese desplazamiento resulta porque el hombre se deja cegar por la hermosura. ${ }^{20}$ La agencia femenina sólo es posible mediante la reificación de su cuerpo en una sinécdoque que la reduce a la pasividad de una "golosina” (244). Así, si la mujer es agente lo es sólo porque el hombre goza o gusta de ella; si es peligrosa es porque el hombre se rinde ante ella. En un momento revelador, el autor comenta: "Son muy lindas las sabandijas, y que tienen otro privilegio, que son muy queridas, que de aquí nace el daño” (245). El alegato del poder femenino no se sostiene porque se funda exclusivamente en su goce activo por un agente masculino.

Después de recrear un mundo donde reina el caos total, el autor concluye abruptamente con un catálogo. Esta última parte del texto muestra una composición rigurosamente ordenada donde desfilan los hombres en cuyas manos ha estado el orden de la Real Audiencia de Bogotá. ${ }^{21}$ El catálogo consiste principalmente en la enumeración cronológica de todos los miembros de la Real Audiencia de Bogotá, y recalca la llegada de nuevos representantes jurídicos. Se ofrece así en él una visión ordenada del sistema jurídicoadministrativo que, dado el análisis anterior de los casos, tiene poca correspondencia con los acontecimientos. ${ }^{22}$ El único espacio en que ese orden racional se mantiene es en esta

En otras palabras, la situación novogranadina no se critica desde una perspectiva cristiana, sino que la cita bíblica se utiliza para efectuar la crítica del caos novogranadino. La preocupación principal del autor no es religiosa ni moral, sino local y de carácter civil.

${ }^{20}$ En su tesis doctoral Hernández-Torres analiza aquéllos momentos en que Rodríguez Freyle pronuncia algunos juicios contra el hombre en general y concluye que estas vituperaciones hacia el hombre sirven para recalcar la misoginia. Véanse en particular las páginas 158-64.

${ }^{21}$ Justo antes de comenzar el catálogo final, el autor equipara su texto a una obra teatral: "Para que se entienda mejor esta representación del mundo, es necesario que salgan todas las personas al tablado, porque entiendo que es obra que ha de haber qué ver en ella, según el camino que lleva” (285). En su estudio “Jorge Voto, el maestro de danzar: la teatralidad en un caso de El carnero", Karen Stolley sostiene que las técnicas dramáticas de la comedia del Siglo de Oro sirven de modelo para las viñetas narradas. Este paralelo subraya la importancia de las intrigas y traiciones que caracterizan cada caso. Sin embargo, me parece que la obra responde a mucho más que las expectativas de un público acostumbrado a comedias de honor o de capa y espada, como sugiere Stolley. Rodríguez Freyle anuncia que "ha de haber qué ver en ella [en su representación del mundo]”, y recrea el mundo novogranadino de una manera deliberada con el fin de validar su papel de juez y jurado ante el comportamiento poco honorable de ciertos “personajes” del Nuevo Reino de Granada. De ahí sus constantes autorreferencias y su insistencia en reivindicar a algunos representantes y condenar a otros. ${ }^{22}$ En esta tercera parte, el fragmento que corresponde al quinto caso ofrece un fuerte contraste con la narración de la parte anterior. En este catálogo Rodríguez Freyle resume en unas líneas la narración que describe a lo largo de varios capítulos en la segunda parte de la obra: "los dos prendieron al visitador Juan Bautista de Monzón, el cual entró en esta cuidad el año de 1579 [...] el cual suspendió al presidente don Lope Díez de Armendáriz, y la Real Audiencia prendió al visitador. Estando preso, murió dicho presidente en esta ciudad. [...] Al negocio de la prisión del licenciado de Monzón y que acabase la visita, envió su Majestad, Philipo II, [...] por oidores de La Real Audiencia, el licenciado 
tercera parte; aquí no figuran los alborotos y embrollos ocasionados por los mismos representantes que tenían a su cargo el mantener el orden político colonial. En este catálogo final se incluyen escasas referencias a la mujer y en la mayoría se la trata literalmente como objeto, incorporándola a una lista de productos importados al Nuevo Reino: “el gobernador Jerónimo Lebrón vino a él con doscientos hombres. Trujo las primeras mujeres y muchas mercadurías de Castilla, que también fueron las primeras” (312). "Las primeras mujeres" no sólo aparecen como anónimas, sino como otro objeto mercantil más que llegó para circular en el Nuevo Reino. Excluida como partícipe o agente del orden jurídico-político, la mujer está fuera del sistema donde según el autor supuestamente "manda".

Se puede concluir, entonces, que la atención prestada a la mujer en El carnero es una estrategia empleada por su autor para efectuar una crítica política que no hubiera podido expresar abiertamente. ${ }^{23}$ Escondido tras la falda de la mujer hermosa, Rodríguez Freyle pone al descubierto el comportamiento desordenado -léase feminizados- de los representantes locales del sistema jurídico español. Aunque se refiere a las mujeres como las protagonistas del caos novogranadino, los verdaderos agentes móviles en los casos narrados son los representantes de la Real Audiencia: oidores, visitadores, fiscales y alguaciles. La figura de la mujer, a quien se le imputa manipular el sistema jurídico, se usa para revelar y criticar un contexto político en que rigen los excesos de hombres apasionados como Jiménez de Quesada, Zorro, Céspedes, Tafur, Ruiz de Orejuela, Roldán, Zorrilla, Orozco y Sepúlveda. Mediante esta estratagema, los oficiales de la Corona son "feminizados" por su desmesura y su conducta apasionada e irracional. Como consecuencia de estos excesos no sólo descuidan las responsabilidades que les corresponden, sino que además manipulan de manera caprichosa - léase femenina - el mismo sistema que en principio deberían sustentar. El declarar que "las mujeres son las que comúnmente mandan el mundo" constituye un doble gesto típico del autor novogranadino y representa a la vez su propuesta más subversiva. Presentando hiperbólicamente el poder de las mujeres, Rodríguez Freyle termina diluyendo su condena en lo abstracto y lo universal. Sin embargo, la especificidad de los casos relatados en El carnero necesariamente nos remite al ámbito concreto novogranadino donde se deja al descubierto que los representantes de la Corona -

\footnotetext{
Alonso Pérez de Salazar, el licenciado Gaspar de Peralta, y por fiscal el doctor Francisco Guillén Chaparro" (315). No se hace mención de los enredos que se describen en la segunda parte de la obra. Aún la prisión del visitador y del presidente se presenta sin explicaciones, divagaciones o juicios. ${ }^{23}$ Según elabora Michel de Certeau en su obra The Writing of History, todo discurso histórico es un proceso o una negociación entre la historia que se narra y las circunstancias históricas del mismo historiador. El caso particular de Rodríguez Freyle ofrece un ejemplo extremo de este proceso histórico. En su "Advertencia al lector" el autor alude a su intención de librarse de lo que él llama "algún áspid venenoso”. La víbora a que se refiere podría ser la censura pero, según Mason Seider, el manuscrito original nunca llegó a ser inspeccionado por la censura. Este detalle no sería sorprendente ya que las Audiencias tenían autoridad general sobre el examen y la censura de los libros impresos en las colonias, particularmente de libros que narraban las historias del Nuevo Mundo, autoridad que se les concedió por una serie de leyes promulgadas en diferentes momentos desde 1556 a 1668 (Recopilación de Leyes de los Reinos de Las Indias, Libro II, Título XV, Leyes 1-15). El estudio de este aspecto de la obra requeriría una extensa investigación de archivos; la conexión entre la reticencia del autor y su situación histórica se propone aquí como posible punto de partida.
} 
impulsados por la pasión y no por su razón— — han ocasionado el desastre político y civil de la colonia.

\section{BiBLIOGRAFÍA}

Alstrum, James J. “The Real and the Marvelous in a Tale from El carnero”. Kentucky Romance Quarterly 29 (1982): 115-24.

Bruno, Charles. (Re)writing History in Juan Rodríguez Freile’s 'Conquista y descubrimiento del Nuevo Reino de Granada': Myth, Irony, Satire. Diss. University of Wisconsin, 1990. Ann Arbor: UMI 9024754.

Chang-Rodríguez, Raquel. "Las máscaras de El carnero”. Violencia y subversión en la prosa colonial hispanoamericana: siglos XVI-XVII. Madrid: Studia Humanitatis, 1982. 41-61.

"Realidad y fantasía en El carnero". Otros mundos otros fuegos: fantasía y realismo mágico en Iberoamérica. Donald A. Yates, ed. East Lansing: Michigan State University, 1975. 73-76.

Cunningham, C. H. The Audiencias in the Spanish Colonies As Illustrated by the Audiencia of Manilla. Berkeley: University of California Press, 1919.

de Certeau, Michel. The Writing of History. Tom Conley, trad. Nueva York: Columbia University Press, 1988.

Gómez Hoyos, Rafael. Las Leyes de Indias y el derecho eclesiástico en la América Española y las Filipinas. Medellín: Universidad Católica Bolivariana, 1945.

Herman, Susan. "Conquest and Discovery: Subversion of the Fall in El carnero". MLN 108 (1993): 283-301.

Hernández-Torres, Ivette. El contrabando de lo secreto: la escritura de la historia en El carnero de Juan Rodríguez Freile. Diss. Brown University, 1988. Ann Arbor: UMI, 1988. 9830452.

Mason Seider, Margaret. “A Literary and Historical Analysis of El carnero by Juan Rodríguez Freile”. Diss of University of Kentucky, 1980.

Ortiz, Gloria M. "Juan Rodríguez Freile: Su actitud ante la mujer en El carnero”. Essays in Honor of Jorge Guillén on the Occasion of His 85th Year. Cambridge, MA: Adeul, 1977. 52-63.

Recopilación de Leyes de los Reinos de Las Indias, 4 vols. Prólogo por Ramón Menéndez y Pidal. Estudio preliminar de Juan Manzano Manzano. Madrid: Ediciones Cultura Hispánica, 1973. Libro II, Título XV, Leyes 1-15.

Rodríguez Freyle, Juan. Conquista y Descubrimiento del Nuevo Reino de Granada. Jaime Delgado, ed. Madrid: Historia 16, 1986.

Stolley, Karen. “Jorge Voto, El maestro de danzar: la teatralidad en un caso de El carnero". Revista de Crítica Literaria Latinoamericana 28/2 (1988): 291-304.

Tuana, Nancy. The Less Noble Sex: Scientific, Religious, and Philosophical Conceptions of Woman's Nature. Bloomington: Indiana University Press, 1993. 